\section{THE SUN AND STARS}

III.

\section{The Spots}

I $\mathrm{N}$ the large photographs now secured at Meudon and in India, and smaller ones now received from India, the Mauritius, and Australia, showing the spots as they are photographed there, I am glad to say almost every day now, on a scale of 8 inches to the sun's diameter, we get wonderful records of what a spot really is, and how it changes.

In a normal spot the exterior shade is called the penumbra. The inner darker one is called the umbra, and very often there is a deeper shade still, which is called the nucleus. In some spots there are many umbræ for one penumbra; and very likely, if one had examined them carefully with the telescope at the time, one would have found that each had its interior nucleus. The idea is that we have at the edge of the penumbra, where the penumbra joins the photosphere, the greatest height of the spot; that the penumbra is an incline going down as gradually as you like, but still down, so that the level of the photospheric stuff, whatever it is, at the edge of the umbra, is below what it is at the edge of the penumbra.

In the penumbra the domes seen on the general surface are drawn into elongated shapes, hence we speak of the "thatch" on the penumbra. Visually the part of the penumbra adjoining the umbra seems brighter than that adjoining the photosphere. In photographs this is not so.

Now, if the view that the spots are cavities be correct, and the appearances they put on in travelling over the sun are suf-

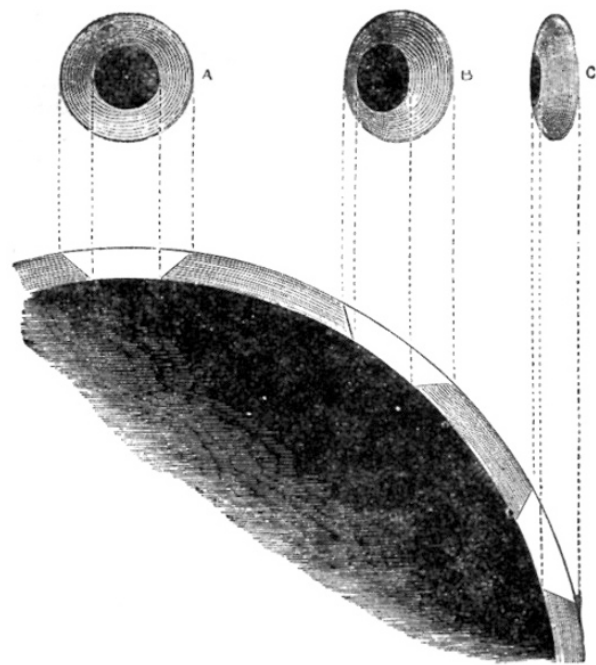

FIG. 4.-Appearances presented by spots. $A$ is the centre of the disk; $B$ between centre and limb; $c$, near the limb.

ficient to prove it, it will be clear that there ought to be occasions when a spot going over the limb should show as a depression. The idea that sunspots are cavities is a very old one. It was first put forward by Wilson of Glasgow in the last century ; but it was not so easy to demonstrate it to a large audience in the days when one had no photographs.

Here is a photograph showing the retreat of a sunspot over the edge of the sun in $\mathbf{1 8 8 4}$. We see that it writes its record in an unmistakable notch at the limb of the sun (Fig. 5).

In other photographs we can conveniently study the connection between the faculæ and the spots, especially if the spots be near the limb; the neighbourhood of spots in this position is very rich in faculæ.

When we come to examine these spots carefully, we find that there are apparently in the main-(I want to speak as guardedly as I can)-two different kinds. Some spots seem to be pretty regular, and to undergo no very violent commotion. I mean that the penumbra and the umbra are not so tremendously contorted and mixed up as sometimes happens; and, again, the ridge of facula round the spot is not so honeycombed

${ }^{x}$ A Course of Lectures to Working Men delivered by J. Norman Lockyer, F.R.S., at the Museum of Practical Geology. Revised from shorthand notes. Continued from p. 429 . by convection-currents and the results of convection-currents. On the other hand, as representing the other class where we get violent action, there seems to be no limit to the enormous energies indicated, and the areas over which these energies hold their sway. I believe that one spot, or at least a spot system, was observed in 1858 , of 140,000 miles or eighteen earth-diameters in length. Telescopic examination of each minute part of these enormous disturbances indicates that the most violent changes

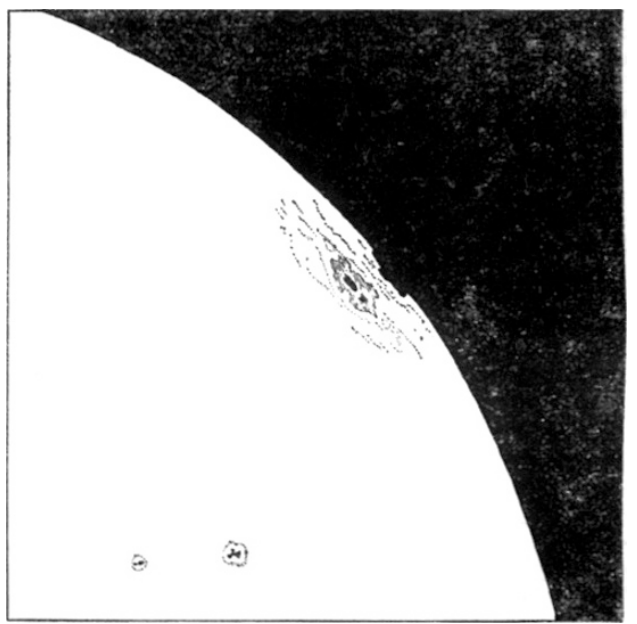

Fig. 5.-Copy of part of a photograph taken at Dehra Dun in 1884 , showing a sunspot passing over the Sun's edge.

are going on-changes which the eye can detect, after a few minutes' interval, in different parts of the spot (see Fig. 6).

\section{The Hislory of a Spot}

A spot seems to be the first disturbance of the photosphere in the region where it is formed. I mean the facula follows,

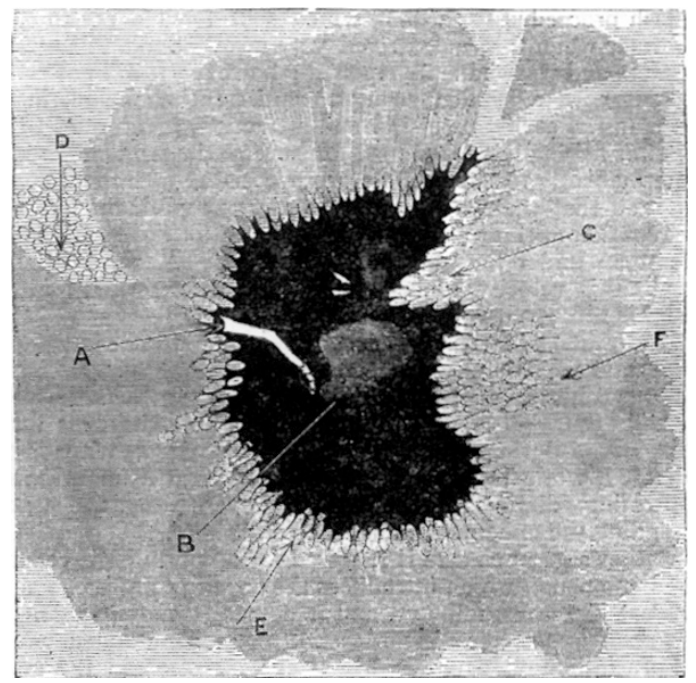

FIG. 6.-Sunspot showing details of the penumbra. The dark portion in the centre is the umbra, the surrounding half-tone is the penumbra. A, a "bridge" or tongue of facula being carried over the umbra; $B$, clouds forming at the end; $c$, part of the penumbra being driven over the spot (the domes are drawn out); $D$, domes on photosphere ; $F$, "thatch" on penumbra.

and does not precede, the spot. On this point I first quote Dr. Peters, ${ }^{1}$ one of our highest authorities :-

"The spots arise from insensible points, so that the exact moment of their origin cannot be stated; but they grow very

${ }^{1}$ Proceedings of the American Association for the Advancement of Science, vol. ix. 
rapidly in the beginning, and almost always in less than a day they arrive at their maximum of size. 'Then they are stationary, I would say in the vigorous epoch of their life, with a welldefined penumbra of regular and rather simple shape. So they sustain themselves for IO, 20, and some even for 50 days."

I next quote the Rev. S. I. Perry, one of the most constant of modern solar observe:s :-

"And, to begin with spot-formation, we find almost invariably that large solar spots start life as little dots, frequently in groups, and then grow at once with enormous rapidity. A spot wil often attain its full size in 5 or 6 days, although exceptionally large ones occasionally occupy a longer time in their first development. If no remarkable increase is noticed in a spot within 2 or 3 days from its birth, it will in all probability never attain to any considerable size. The solar surface has repeatedly been examined with the greatest care, in regions where considerable spots have broken out on the following day, without detecting any marked disturbance or other sign announcing a probable outburst. No satisfactory exceptions to this have as yet been noticed."

The second state of a spot's history presents us with phenomena of reaction, as if the material carried in the first instance below the upper level of the photosphere had produced a disturbance in the lower regions, indicated by the increase in the quantity and brilliancy of the faculous matter and its separation into small masses, while at times the umbra of the spot becomes distinctly coloured.

I again quote Dr. Peters :-

"The notches in the margin, which, with a high magnifying power, always appear somewhat serrate, grow deeper, to such a degree that the penumbra in some parts becomes interrupted by straight and narrow luminous tracts,--already the period of de cadence is approaching. This begins with the following highly interesting phenomenon. Two of the notches from opposite sides step forward into the area, over-roofing even a part of the nucleus; and suddenly from their prominent points flashes go out, meeting each other on their way, hanging together for a moment, then breaking off and receding to their points of start ing. Soon this electric play begins anew and continues for a few minutes, ending finally with the connection of the two notches, thus establishing a bridge and dividing the spot into two parts. Only once I had the fortune to witness the occurrence between three advanced points. Here from the poin A a flash proceeded towards $B$, which sent forth a ray to mee the former when this had arrived very near. Soon this seemed saturated, and was suddenly repelled; however, it did not retire, but bent witl a sudden swing toward $\mathrm{C}$; then again, in the same manner, as by repulsion and attraction, it returned to $B$; and, after having thus oscillated for several times, A adhered at last permanenity to $\mathrm{B}$. The flashes proceeded with great speed, but not so that the eye might not follow them distinctly. By an estimation of time and linown dimension of space traversed, at least an under limit of the velocity may be found; thus, I compute this velocity to be not less than $200,000,000$ metres [or about 120,000 miles] in a second.

"The proccss described is accomplished in the higher photosphere, and seems not to affect at all the lower or dark atmosphere. With it a second, or rather a third, period in the spot's life has begun, that of dissolution, which lasts sometimes for Io or 20 days, during which time the components are again subdivided, while the other parts of the lumin us m irgin, too, are pressing, diminishing, and finally overcasting the whole, thus ending the ephemeral existence of the spot.

"Rather a good chance is required for observing the remarkable phenomenon which introduces the covering process, since it is achieved in a few minutes, and it demands, moreover, a perfectly calm atmosphere, in order not to be confounded with a kind of scintiliation which is perceived very often in the spots, especially with fatigued eyes. The observer ought to watch for it under otherwise favourable circumstances when a large and tenor twenty-days'-old spot begins to show strong indentations on the margin."

The scintillation referred to by Dr. Peters is perhaps associated with a phenomenon which has been described by $M$. Trouvelot, ${ }^{1}$ who has observed the faculous masses to subdivide into smail flakes which vibrate rapidly, producing the effect of a snow-storm alove the umbra, when these dissolve into blue or violet vapours.

It happens sometimes also near groups of spots which are I Bulletin Astronomizue, vo!. ii. endowed with great activity that perturbations are observed which are so violent that the adjacent photosphere is shaken to its foundations, cracks, and, on opening, forms sinuous crevasses which extend to considerable distances, sometimes connecting the most distant spots with each other.

From the instant of their apparition the crevasses-even thos which are the narrowest-show a striated and filamentous structure, which presents the greatest analogy with the penumbræ of spots; only, instead of inclining and forming a sort of slo se like that on the penumbra, the filaments which form entirely the sides of the crevasses are vertical, and are all directed towards the centre of the sun.

When these crevasses have a certain duration they widen sometimes here and there, especially when they bifurcate and send branches in another direction. In this case it is not rare to see forming a strait and lengthened umbra when, at the same time, the vertical filaments having now more roo:n raise their lower extremities.

We have seen that the last act in the history of a spot is its invasion by the faculæ. These faculæ remain long after the spot has entirely closed up, and in this connection it is important to remark that new spots very often break out in the old place. These of course, unlike the first spot in that position, will appear to be preceded by faculæ.

There is a great deal more that I might say about spots. It is a very tempting subject, but there is so much more to be referred to. The papers which have recently been printed by the Rev. S. J. Perry ${ }^{1}$ and M. Trouvel ot represent some of the most careful modern examination of the solar surface, and there is really a very great deal to be learnt from them; and fortunate it is that much which this new work has brought out in the plainest way has reference to a region of fact of very great importance to any one who wants to be able to answer for himself, as well as he can, the question, What is a sun? For instance, M. Trouvelot discovered about ten years ago that, although, as we shall see presently, ordinary sunspots have a very definite place of their own on the sun, there is a kind of spot which is not so confined. These he calls veiled spots; and I gather from his description that his opinion is that the photosphere is driven down there to a certain extent, but not driven down sufficiently to give us the dark appearance which we get in the other cases.

\section{Spots cauted by Descent of Cooled Material}

It has already been suggested in preceding paragraphs that in the spot region we cannot really be dealing with any violent changes of pressure, but we may be dealing with very violent changes of temperature. We can see that it is the most natural thing in the world to suppose that in an atmosphere like the sun's, seeing that there i; enormous radiation, and therefore cooling at the exterior, there must be a descent of solid particles into the interior heated region. Now, can we associate this with spot phenomena?

Yes, we can, and we are absolutely driven to it. We have already seen that the spot, when it travels over the limb, is a hollow. We also find when we examine a spot with the spectroscope that certain vapours get very much denser, as if they were being crushed torether into a certain limited region either by an upthrust or a do vnfall. Which? Well, the spectroscope answers that question for us quite perfectly, because it shows that the vapours are absorbing, and therefore that they are cooler than the photospheric material immediately underlying them, and that they have not an excess of radiation, as they would have if they came up from below; the spectroscope then certainly justifies the view that a spot is really the result of a downrush; the vapours there are cooler, as they should be if they come from a cooler place; they are denser, as they should be, if they are descending rapidly into a place which is more or less confined; and, more than all, the change of the refrangibility of certain lines enables us to determine roughly the rate at which these descents take place. A very common velocity is 30 miles a second-not 30 miles a minute or 30 miles an hour, but 30 miles a second.

Our final idea with regard to the spots then is that they are depressions, that in fact we may regard them as shallow saucens or cups filled with the cooler vapours brought from the upper regions of the solar atmosphere. This is merely a physical conception. What we have next to do, if possible, is to add a little 
chemistry, to make a more or less detailed examination of the materials - of the various chemical substances-in them.

\section{The Chemistry of the Spots}

Now from what has been already said we at once see that if we get a downrush of solid bodies, such as cooled iron masses which are derived from the condensation of the iron vapour, and which we may regard as solar meteorites, from the top of the sun's atmosphere down to the photosphere, we shall have, if that quantity be great enough in the spot region, a considerable dimming of the sun's light, by reason of the fact that we have an infinite number, or a very large number, of solid bodies stopping the light from that particular part of the sun. We shall have in that way then a continuous absorption of the sun's light; that is to say, the red light, the yellow light, the green light, the blue light, and so on, will all be more or less stopped, and that part of the sun will, from that cause alone, look dimmer. Further, if we have any vapour approximating in molecular structure to the chlorine vapour to which I drew your attention before, we shall have an absorption of another kind; we shall have a special stopping of the blue light of the sun, making, therefore, the sunlight yellower than it otherwise would be. Again, if we have other substances associated with these spots in the state of fine vapour in a state of incandescence, we shall have such absorption indicated by the darkening of certain of the Fraunhofer lines, and by the widening of them as well as the clarkening of them if the quantity of any particular vapour is considerable, and we shall also get new lines if new substances are produced or their existence revealed by these conditions.

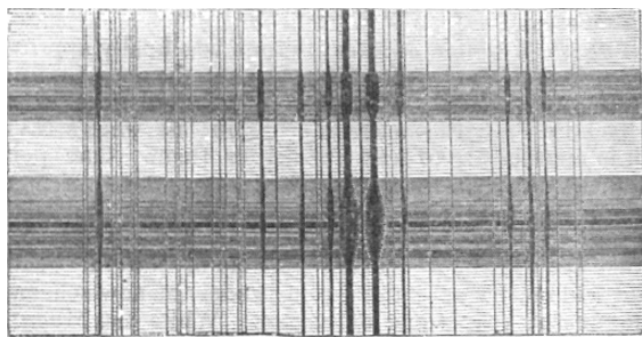

FIG. 7.-The spectra of two sunspots, showing the general darkening, and that certain lines are widened while others are not.

Now, I propose with regard to this point, seeing that our time is limited, to confine myself to the observations that have been made on the sun's spots at South Kensington since the year 1879. From that period some 700 spots have been observed. Of that number some 200 have been discussed; that is to say, maps have been made, and we have endeavoured to see along which line it was best to push on the work. But this climate of ours is not a particularly good one for observations of this kind, especially in London, because there is a good deal of smoke, and it is almost as difficult to see through a smoke cloud as it is through one of the ordinary kind. Still, in that time a considerable number of observations have been made altogether; and, to guarantee us as far as possible against bad climatic conditions, what has been done in the case of each spot has not been to observe all the lines which are specially affected, but to content ourselves with getting the results with regard to twelve lines, six in the green and yellow, and six in the blue. In that way, as these observations can be recorded in about an hour, all the observations made from 1879 to the present time are strictly comparable.

Before I state exactly what results we did get it is worth while for one moment to consider what results we should get if the old view of the chemical structure of the solar atmosphere were correct. This view is that most of the absorption which produces the Fraunhofer lines in the solar spectrum, especially those due to the absorption of the vapours of chemical substances of high atomic weight, takes place close to the photosphere, which is practically the place where the spots live. Therffore we should expect to see :-

(I) The same lines constantly thickened, as the ordinary solar spectrum is constant.

(2) The same lines of a substance widened in all spots, in which we have evidence that that particular substance is p:esent, or the lines thinning out in all cases in the same order.
(3) No lines but those visible in the general spectrum.

(4) Motion indicated by one line of a substance indicated by all.

If the old view were true, that we have iron vapour among the other vapours in the atmosphere of the sun-nickel vapour, magnesium vapour, and so on, it would not be at all out of the way to suppose that some spots might chiefly consist of iron vapour, whereas another spot might be chiefly filled with nickel vapour, or with magnesium vapour, and so on.

With reference to $(2)$ it may be explained that in the case of a spot which we can imagine to contain a very large quantity let us say of iron vapour, and a very small quantity of magnesium vapour; by a laboratory process which had been worked out before this work was commenced, it was easy to make a rough, but still a very useful, quantitative guess as to their relative proportions, because it has been found in laboratory work that if we only have a very small quantity of one vapour, let us call it vapour $a$, in a mixture of other vapours, $b, c$, and $d$, then we shall not get all the lines of $a$; we shall only get some of them, the longest lines; and if the quantity $a$ is very small indeed, then we shall only get one line-the longest, in the spectrum of the vapour.

The method of mapping adopted may next be stated. In order to get as much light as we could out of the work, first of all the Fraunhofer lines were mapped in a manner which enabled anybody who took the trouble to look at the map to see which was darkest. In addition to those Fraunhofer lines information is given showing the origin of them.

I should tell you that it has been found since Kirchhoff's first researches that it does not do to talk about the spectrum of a substance as if it were an unchangeable thing. To be precise we must refer to the spectrum at the temperature of the arc ; or at the temperature of the electric spark with a jar or without a jar; or at the temperature of the oxy-laydrogen flame. These spectra are very different indeed, not with regard so much perhaps to the actual lines which we see in any case, but chiefly with regard to the intensity of the lines as seen in one spectrum and in the other.

Thus it was useful to compare the lines of a substance as seen in the arc and spark with that seen in the spots, and that, so to speak, formed the ground-plan of the maps. The work to be done was to observe all the lines most widened in a region of the spectrum, and see whether they were absolutely unchangeable or whether they were not.

The diagram shows a part of one of these maps dealing with the first Ioo observations. The Fraunhofer lines are at the top; the lengthening of the lines representing the intensity, that is to say, the longest line is the darkest. Below are the lines of the substance being specially studied seen in the electric arc, the longest being the brightest; and lower still the lines seen in the electric spark, the longest line alco being the brightest.

We observe in the first place that there is a very considerable difference in these two spectra. We have a considerable number of lines seen in the arc, and seen in the solar spectrum among the Fraunhofer lines, which are not seen in the spectrum of the spark, the temperature of which of course is assumed to be very much higher than the temperature of the arc.

Again we may have a very faint line at the temperature of the arc, which is considerably intensified when we pass to the temperature of the spark. There are, again, other lines seen nearly of the same lengtly both in the arc and in the spark.

Now, when we first mapped the spot observations, the maps did not indicate the origin of the lines, and when there was a great variation in the lines discovered it was a fair thing to say that the explanation lay in the fact that some of the lines belonged to one substance, and some to another. Let us call those two substances $a$ and $b$. In some spots we have more of $a$ and in other spots we have more of $b$. That of course was very good reasoning, so good that it was necessary to undertake a complete discussion in the case of each element. In this case the spot lines studied are not all the lines which were seen in spots, but the lines of one substance. Now the moment this work was begun strange restits appeared, and the matter became difficult, because we should have imaginel a priori that if the same substance were always present in the spot we should always have got the same spectrum, or, at all events, a spectrim along that line to which 1 have already referred, viz., that if the relative quantity of the vapour were less the number of its lines would be reduced, and at last when the quantity was the least possible the number of lines would be the least possible. I must call 
your attention to the fact that we found inversions, as they are now called; that is to say, to take an instance, if we represent three lines of a spectrum by $a, b$, and $c$, we have found among the most widened lines in spots $a$ without $b$ and $c, b$ without $a$ and $c$, and $c$ without $a$ and $b$. Now that is a condition of things impossible to understand or explain on the old view.

We next continued the discussion over another region of the spectrum, and we found that the result held absolutely good, that is to say, in other regions we got these same inversions. If we look at a map belonging to another period, although the lines change, the inversions remain, and the lines behave very much in the same way as the other. This result is quite constant for all regions of the spectrum examined. Hence, finally, we learn that these inversions hold good for different periods, and for different parts of the spectrum; and we have found that spectroscopically any one vapour in the spots behaved in exactly the same way as various mixtures of many vapours would be bound to do.

The result of this inquiry with regard to chemical substances which have been most carefully worlied out, is indicated in the accompanying table, giving the result of the work for two years from 200 spots.

Statistics of the most Widened Lines secn in 200 Sunspots at Kensington

\begin{tabular}{|c|c|c|c|}
\hline \multicolumn{2}{|c|}{$\begin{array}{l}\text { Total number of } \\
\text { lines in part } \\
\text { of spectrum } \\
\text { discussed }\end{array}$} & \multicolumn{2}{|c|}{$\begin{array}{l}\text { Total number of } \\
\text { lines widened }\end{array}$} \\
\hline 172 & $\ldots$ & $\ldots$ & 72 \\
\hline 120 & $\ldots$ & $\ldots$ & $3^{8}$ \\
\hline 24 & $\ldots$ & $\ldots$ & 9 \\
\hline 19 & $\ldots$ & $\ldots$ & 5 \\
\hline 17 & $\ldots$ & $\ldots$ & 3 \\
\hline 17 & $\ldots$ & $\ldots$ & 7 \\
\hline 15 & $\ldots$ & $\ldots$ & 9 \\
\hline 14 & $\ldots$ & $\ldots$ & I \\
\hline 14 & $\ldots$ & $\ldots$ & 2 \\
\hline 13 & $\ldots$ & $\ldots$ & 4 \\
\hline I 2 & $\ldots$ & $\ldots$ & I \\
\hline IO & $\ldots$ & $\ldots$ & I \\
\hline IO & $\ldots$ & $\ldots$ & I \\
\hline 7 & $\ldots$ & $\ldots$ & 2 \\
\hline
\end{tabular}

In these 203 spots out of 172 lines of iron which we might have seen only 72 were observed altogether; out of $\mathrm{I} 2 \mathrm{O}$ lines of titanium which we might have seen only 38 were seen; and then the number goes on decreasing : 24 in the case of nickel, of which 9 were seen; I9 in the case of zinc, of which 5 were seen; I 3 of magnesium, of which 4 were seen; I 2 of platinum, of which I was seen, and so on.

The final upshot is, therefore, that at the spot-level we do not see the Fraunhofer spectrum, as we ought to do on the old theory. What we do see is a small percentage of the lines, and we see them under conditions which are entirely unexpected. No one, I think, who knew anything about spectrum analysis would have anticipated the result which we have got at Kensington in these 700 observations.

These, though the earlier results, are not the only results which we may hope to get by going on with the work. At present we have limited ourselves to recording the dates of the spots. But this is not enough ; we must know the actual positions of the spots on the sun. We must note whether each particular spot is in the northern hemisphere or in the southern hemisphere, with the view of determining whether there is any chemical difference between the north part of the sun and the south part; and then again we shall have to compare the latitudes of spots, with the view of determining whether there is any difference in the chemistry of the spots according to the latitude. I may tell you that we are working at that particular point just now, and it really does look as if the sudden changes in the spectra recorded may have been due to the fact that the spots compared were spots varying very considerably in latitule, and it would not surprise me to find that spots which are very like each other in their spectra will be found to be situated more or less in the same degree of latitude, - whether the same degree of latitude north or south we do not know. And there is another question, too. I pointed out that there is a considerable number of lines seen in the spectrum of the arc which are left out of the spectrum of the spark. Now, will that help us at all in our inquiries? I think perhaps it may. Everybody assumes that the electric spark is hotter than the electric arc. If that be so, the lines which we see at the temperature of the arc, and which we do not see at the temperature of the arc only, may represent the lines due to cooler vapours-more complex molecular groupings it may be, which can exist in the cooler temperature, but which entirely break up on the application of a higher one. If that be so we shall be able to sort out the spots more or less according to their temperature.

Though the results have not been shown on the maps, the lines visible in the spectrum of some substances at the temperature of the oxy-hydrogen jet have been observed. Everybody assumes that the temperature of the oxy-hydrogen jet is lower than the temperature of the electric arc or spark; so that, if we can get a spot which gives us those lines thickened only which we see at the temperature of the oxy-hydrogen jet, we should be perfectly justified, I think, in saying that that was a relatively cool spot; whereas, if we saw a spot which only had those lines thickened which are intensified on the passage from the temperature of the arc to the temperature of the spark, we should be justified in saying that that spot was very much hotter. I only throw this out as an indication of the kind of result which probably future working and future thought will bring out, and that we are by no means at the end of the work yet.

(To be continusd.)

\section{NORMAN LOCKYer}

\section{UNIVERSITY AND EDUCATIONAL INTELLIGENCE}

OXFORD. - The new Medical Statute was finally approved by Convocation on March 16 . The scope of the new Statute and its bearing on the study of medicine at Oxford were so clearly described by Prof. Burdon-Sanderson in last week's NATURE, that it is unnecessary to refer further to them. One point insisted on by the Professor, that the present student of medicine wastes his first year over Pass Moderations, has not yet been corrected. The Moderations Committee are still deliberating, but there seems little doubt that students of Natural Science in Oxford will receive substantial relief under the new scheme.

The present year is one of reform. While the Moderations question is still under debate, a new and much-needed reform has been sprung upon the University. The old Examination in the Rudiments of Faith and Religion has by common assent become out of date. Last week the preamble of a new Statute was passed nemine contradicente in Congregation. We must wait till next term to learn the fate of the Statute itself. It seems time that the University should grant degrees without demanding an intimate knowledge of the Thirty-nine Articles.

CAMBRIDGe. - It has been decided to establish a Tripos Examination in Engineering, to be combined with the present Natural Sciences Tripos. The general basis is that, as an alternative to the present First Part of the Tripos, an examination in certain mathematical subjects useful in engineering, physics, chemistry, and theory of structures shall be held, to be followed by a practical examination. Those who pass this will be entitled to a degree in honours. A later examination, concurrent with the second part of the Natural Sciences Tripos, is to consist of advanced papers in Physics, Chemistry, and Engineering, distinction in one or more of which is to entitle a student to a first class. When the complete scheme is published we shall give full details.

\section{SCIENTIFIC SERIALS}

The Fournal of Physiology for November 1885, vol. vi. No. 6 , contains:-On a double differential rheotome, by Dr. W. D. Samways (plate 7). The instrument is described and figured.On the blood of Decapod Crustacea, by Dr. W. D. Haliburton (plate 8). Assisted in part by a grant from the British Medical Association, the author has studied the blood in the lobster, the edible crab, the crayfish, Astacus, and Nephrops norvegicus; and he treats of its colour, constituents, and coagulation. He ascribes the clot as due to the formation of a body scarcely to be distinguished from the fibrin of vertebrate blood, and believes that its formation is due to a ferment action, which latter is derived from the amœboid corpuscles of the blood. At the close of the memoir the author treats of the comparative aspects of crustacean 